\title{
NUTRITIONAL AND IMMUNOMODULATORY FUNCTION OF METHIONINE IN POULTRY DIETS - A REVIEW*
}

\author{
Jan Jankowski ${ }^{1 \star}$, Magdalena Kubińska ${ }^{1}$, Zenon Zduńczyk ${ }^{2}$ \\ ${ }^{1}$ Department of Poultry Science, University of Warmia and Mazury in Olsztyn, \\ Oczapowskiego 5, 10-719 Olsztyn, Poland \\ ${ }^{2}$ Institute of Animal Reproduction and Food Research of the Polish Academy of Sciences, \\ Tuwima 10, 10-748 Olsztyn, Poland \\ •Corresponding author: janj@uwm.edu.pl
}

\begin{abstract}
Methionine (Met) plays many important metabolic functions in humans and animals, and therefore may be classified as a functional amino acid (AA). Functional AAs are defined as those AAs that participate in and regulate key metabolic pathways to improve health, survival, growth, development, and reproduction of organisms. As the first-limiting AA in poultry diets, Met affects poultry production parameters such as body weight gains, feed conversion ratio and carcass quality. The results of many experiments on chickens fed diets with different levels of Met (from 0.3 to $1.2 \%$ in the starter period, and from 0.3 to $0.9 \%$ in the grower period) indicate that commercial broiler chickens do not require more than 0.50 and $\mathbf{0 . 3 8 \%}$ Met in starter and grower diets, respectively, for optimum growth and feed efficiency, whereas higher inclusion rates of Met are needed to stimulate immune responses. The results of recent experiments on chickens are insufficient to define the optimal dietary levels of Met, which has been shown to exert immunostimulatory activity. A few experiments on layer hens have demonstrated that Met requirements for immune competence are higher than for optimum production, but the inclusion levels of this AA needed to stimulate the immune system of birds have not been defined. In the absence of such research, it remains unknown whether feeding growing turkeys diets supplemented with Met above NCR recommendations, as suggested by B.U.T. (British United Turkeys), stimulates the immune system of birds.
\end{abstract}

Key words: methionine, metabolism, poultry nutrition, innate immunity, immune function

In intensive poultry production systems, birds selected for a fast growth rate are raised in confinement at high stocking density. It is estimated that 85 to $90 \%$ of performance gains are due to genetic selection, whereas the other 10 to $15 \%$ are the consequence of improvements in nutrition and other management practices (Havenstein et al., 2003). However, selection for growth rate and feed efficiency has resulted

*This study was financed from statutory activity, project No. 0104-0818. 
in a number of negative effects such as reduced resistance to disease (Emmerson, 1997; Leshchinsky and Klasing, 2001) and increased susceptibility to heat stress, which adversely affect the welfare and productivity of poultry (Lara and Rostagno, 2013). Another important consideration is that selection for more effective immune responses results in diminished growth and egg production (Mashaly et al., 2000; Klasing, 2004).

Under high stocking density, birds are exposed to numerous airborne, food-borne and waterborne potentially pathogenic agents, transmitted via direct contact between birds. Viral and bacterial diseases remain a threat to the poultry industry, and countermeasures to prevent and control them are needed due to production losses. Thus, efforts have been made to increase bird resistance to pathogens (Kogut, 2009). Previous research has shown that active modification of chicken gut microbiota may accelerate the maturation of the gut immune system and increase its resistance to infections caused by different pathogens (Crhanova et al., 2011). It is known that some dietary components, such as herbal supplements, can act as an immuno-stimulator in poultry (Hashemi and Davoodi, 2012).

The avian immune system, divided into non-specific and specific immune mechanisms, plays an important role in defence against pathogens, including viruses, bacteria, pathogenic fungi and parasites. Specific immunity includes humoral immunity that involves the synthesis of specific antibodies by B cells (Sproul et al., 2000) and cell-mediated immunity that involves T cells (Radoja et al., 2006). An important component of the body's immune system in humans and animals is gut-associated lymphoid tissue (GALT) (Wershil and Furuta, 2008). Therefore, nutrition plays an important role in the innate immune response to infections in poultry (Kogut, 2009).

Numerous studies in humans (Grimble, 1998; Li et al., 2007; Wu, 2010, 2013; Ruth and Field, 2013) suggest that natural diet ingredients, such as AAs, can stimulate the immune system and improve health. According to Ruth and Field (2013), GALT function is significantly affected by the levels of certain AAs in the diet: glutamine (which reduces inflammation and affects intestinal IgA levels), glutamate (which acts as an immunotransmitter between dendritic cells and T cells), arginine (which reduces inflammatory cytokine levels in the intestines), threonine (necessary for mucin synthesis) and Met+Cys (which reduce intestinal oxidative stress).

Numerous human and animal model studies (Webb et al., 2003; Grimble, 2006; Kim et al., 2006; Li et al., 2007; Fang et al., 2010; Ruth and Field, 2013) have shown that Met is involved in the control of many functions in the body, including participation in protein synthesis in cells of the immune system. Therefore, a similar effect of Met on the immune system of poultry could be expected. The purpose of this review article was to verify the above hypothesis.

\section{Methionine metabolism}

Around 300 AAs occur naturally, but only 20 of them are involved in protein synthesis. AAs and their derivatives transmit nerve signals, regulate cell growth and participate in the synthesis of porphyrins, pyrimidines and urea (Conde-Aguilera et al., 2013). As an essential AA, Met interacts with other nutrients involved in metabo- 
lism (Bunchasak, 2009) and plays a unique role in epigenetic processes by serving as the penultimate methyl donor for mammalian methylation reactions (Waterland, 2006).

Met is an essential sulfur-containing AA that plays many roles in the body, including (1) participation in protein synthesis and the production of other sulfur-containing amino acids (e.g. homocysteine - a sulfur-containing AA which is an indirect product of methylation and transsulfuration (Troen, 2003), (2) acting as a precursor of carnitine and glutathione, thus helping protect cells against oxidative stress (Fang et al., 2002; Li et al., 2007).

Under the influence of methionine adenosyltransferase, Met is converted to Sadenosyl methionine (SAM) (Dunleavy et al., 2006). SAM is a common co-substrate that supplies methyl groups required for various metabolic processes, including DNA methylation and synthesis of RNA, proteins and lipids (Yasuhiko et al., 1982; Wu et al., 2012). In the process of methylation, SAM is converted to S-adenosyl-homocysteine in the presence of methyltransferases. Homocysteine, biosynthesized from methionine, can condense with serine to form cystathionine (Wallwork and Duerre, 1985; Waterland, 2006).

Below is a brief description of Met's metabolic pathway which explains the variety of functions played by this AA in the body (Figure 1).

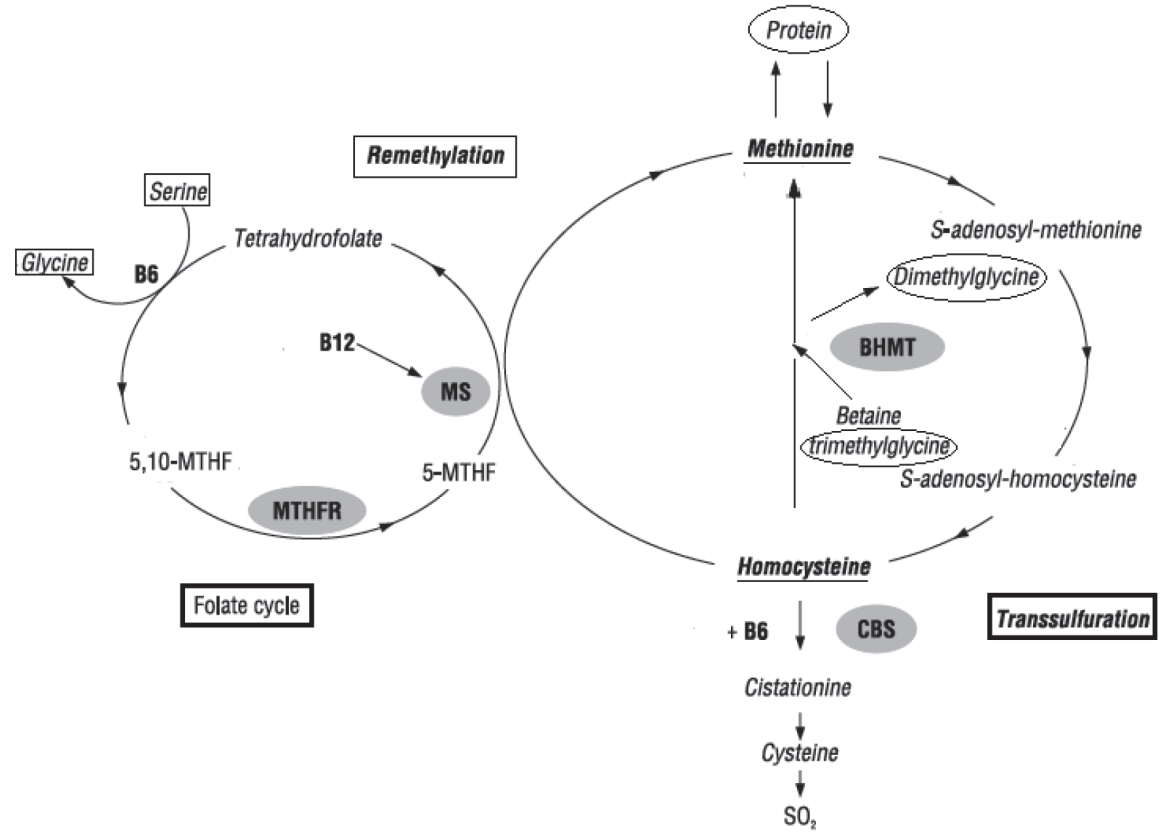

Figure 1. Methionine metabolism (Ito, 1999; Waterland, 2006; Halsted and Medici, 2012) MS - methionine synthase; 5,10-MTHF - 5,10-methylenetetrahydrofolate; 5-MTHF -

5-methylenetetrahydrofolate; MTHFR - methylenetetrahydrofolate reductase; BHMT - betaine-homocysteine S-methyltransferase; CBS - cystatione- $\beta$-synthase 
Permanent bonds are formed between Met and serine during transsulfuration. This reaction requires cystatione- $\beta$-synthase $(\mathrm{CBS})$ and vitamin $\mathrm{B}_{6}$ as the essential cofactor. Homocysteine is metabolized back to Met in the presence of vitamin $\mathrm{B}_{12}$ (Waterland, 2006; Halsted and Medici, 2012). Remethylation requires the presence of MTHRF (methylenetetrahydrofolate reductase) and sufficient quantities of folic acid (Grimble, 2006). S-adenosyl methionine coordinates transsulfuration and remethylation processes by acting as a CBS activator or an allosteric inhibitor of MTHRF (Brosnan and Brosnan, 2006).

Met is also an important source of sulfur in the body (Moore et al., 2004; Bunchasak, 2009) and, as an endogenous antioxidant, it defends cells against oxidative stress (Luo and Levine, 2009).

\section{Nutritional function of methionine in poultry diets}

Met and cysteine (Cys) may be considered to be the principal sulfur-containing AAs because they are two of the canonical 20 AAs that are incorporated into proteins (Brosnan and Brosnan, 2006). From a nutritional point of view, Met is classified as nutritionally essential for animals and humans based on growth or nitrogen balance, whereas cysteine is classified as semi-essential because it can be produced from Met (Grimble, 2006; Baker, 2009; Wu, 2010). Since the carbon skeleton cannot be synthesized by the body, those AAs must be provided in the diet.

Table 1. Requirements for total protein, Met and Met + Cys in chickens and turkeys according to different recommendations (\%)

\begin{tabular}{|c|c|c|c|c|c|c|c|}
\hline \multirow{2}{*}{ Item } & \multicolumn{3}{|c|}{ Broiler chickens } & \multicolumn{4}{|c|}{ Growing turkeys } \\
\hline & starter & grower & finisher & $1-4 \mathrm{wk}$ & $5-8 \mathrm{wk}$ & $9-12 \mathrm{wk}$ & $13-16 \mathrm{wk}$ \\
\hline \multicolumn{8}{|l|}{ Crude protein } \\
\hline $\mathrm{NRC}^{1}$ & 23 & 20 & 18 & 28 & 26 & 22 & 19 \\
\hline $\operatorname{Ross}^{2}$ & $22-25$ & $21-23$ & 19-23 & - & - & - & - \\
\hline \multicolumn{8}{|l|}{ Met } \\
\hline $\mathrm{NRC}^{1}$ & 0.50 & 0.38 & 0.32 & 0.55 & 0.45 & 0.40 & 0.35 \\
\hline $\mathrm{GfE}^{3}$ & 0.42 & 0.38 & 0.32 & 0.55 & 0.49 & 0.41 & 0.40 \\
\hline Ross $^{1}$ B.U.T. ${ }^{4}$ & 0.51 & 0.45 & 0.41 & 0.70 & 0.67 & 0.62 & 0.54 \\
\hline \multicolumn{8}{|l|}{ Met + Cys } \\
\hline $\mathrm{NRC}^{1}$ & 0.90 & 0.72 & 0.60 & 1.05 & 0.95 & 0.80 & 0.65 \\
\hline $\mathrm{GfE}^{3}$ & 0.77 & 0.82 & 0.76 & 0.82 & 0.76 & 0.72 & 0.65 \\
\hline Ross $^{1}$ B.U.T. ${ }^{4}$ & 1.07 & 0.95 & 0.86 & 1.25 & 1.20 & 1.11 & 0.97 \\
\hline
\end{tabular}

${ }^{1} \mathrm{NRC}, 1994$.

${ }^{2}$ Ross (2007). Recommendations for broiler chickens.

${ }^{3}$ GfE. Recommendations for chickens - GfE, 1999; Recommendations for turkeys - GfE, 2004.

${ }^{4}$ B.U.T. (2012). Recommendations for turkeys - B.U.T.

Met plays a vital role in all species, and it is essential in poultry nutrition because rapidly growing birds have a high demand for AAs. The Met content of poultry diets should be adapted to the specific requirements of birds to maintain proper AA balance in the body that stimulates growth, maximizes carcass yield, reduces carcass 
fatness and promotes adequate feed intake to minimize losses and reduce production costs (Bunchasak, 2009; Lemme et al., 2005).

Table 1 presents dietary requirements for total protein, Met and Met+Cys in different poultry groups, according to the recommendations of NRC (1994) and GfE (1999, 2004), and the Ross (2007) and B.U.T (2012) breeding companies. The GfE recommendations regarding dietary Met levels in chickens (1999) and growing turkeys (2004) are similar to NRC recommendations (1994). Only in the starter period, GfE (1999) recommends considerably higher dietary levels of Met and sulfur-containing AAs in broiler chickens. In comparison with NRC, GfE recommends the same Met levels and higher Cys levels in grower and finisher diets for broiler chickens, and higher Met levels and lower AA levels in turkey diets. As shown in Table 1, both companies producing parent stock chickens (Ross) and turkeys (B.U.T) recommend significantly higher levels of Met and Met+Cys than NRC and GfE.

It is generally accepted that Met is the first essential AA in poultry nutrition, which limits the biological value of protein (Meirelles, 2003; Kim et al., 2006; Matsushita et al., 2007). This is confirmed by Table 2 data which shows the amounts of Met and total sulfur-containing AAs supplied by basic components of poultry diets, including cereals and high-protein feeds such as soybean meal, rapeseed meal and grain legumes. Prior to supplementation with synthetic Met, the levels of this AA in all turkey diets were lower than those recommended by NRC (1994) and B.U.T.

Table 2. Content of crude protein (CP), methionine (Met) and methionine+cystine (Met+Cys) in turkey diets without added Met

\begin{tabular}{l|c|c|c|l}
\hline \multirow{2}{*}{\multicolumn{1}{c|}{ Diet }} & \multicolumn{3}{c|}{ Dietary content (\%) } & \multirow{2}{*}{ References } \\
\cline { 2 - 4 } & CP & Met & Met + Cys & \\
\hline Corn-wheat-soybean & 20 & 0.30 & 0.65 & Jankowski et al., 2011a \\
Wheat-soybean & 19.7 & 0.27 & 0.62 & Mikulski et al., 2009 \\
Wheat-soybean-rapeseed & 19 & 0.31 & 0.70 & Mikulski et al., 2012 \\
Wheat-soybean-sunflower & 18.6 & 0.32 & 0.66 & Jankowski et al., 2011b \\
Wheat-soybean-grain legumes & 19.5 & 0.24 & 0.65 & Mikulski et al., 2014 (in press) \\
\hline
\end{tabular}

It is known that dietary Met levels affect growth indicators and the quality of animal carcasses (Hoehler et al., 2005; Koreleski and Świątkiewicz, 2008; Wu et al., 2012). The results of experiments with different Met levels in broiler chicken diets, discussed in the next section, are inconclusive. Swain and Johri (2000) noted similar body weight gains and feed efficiency in chickens fed starter diets containing 0.37 to $0.87 \%$ Met. In other studies (Rubin et al., 2007; Deng et al., 2007), Met-deficient starter diets (containing less than $0.31 \%$ Met) decreased the body weights of chickens, and diets with Met levels increased above the NRC (1994) recommendations did not improve productivity. An increase in Met content from 0.5 to 0.7 and $0.8 \%$ did not increase the body weights of chickens and did not improve feed conversion (Elagin and Elzubeir, 2012; Bouyeh, 2012).

Differences in the estimates of AA requirements in growing turkeys (Table 1) were only partially verified in feed trials. In a study of Waldroup et al. (1997), 
whose aim was to evaluate the NRC AA recommendations for Large White turkeys, the effects of feeding diets with eight different AA levels covering 85 to $120 \%$ of AA demand determined by NRC (1994) were compared. It was found that diets formulated to provide $105 \%$ of the suggested NRC requirements were needed to provide maximum body weight gains, feed conversion, and breast meat yield. Lemme et al. (2005) analysed the responses of 36- to 63-day-old B.U.T. Big 6 turkey toms to graded dietary Met + Cys levels. The cited authors compared the effects of feeding diets with six different Met levels $(0,0.2,0.4,0.8,1.3,1.8$ or $2.4 \mathrm{~g} / \mathrm{kg})$ and found that Met+Cys levels needed to ensure the optimal growth of turkeys were higher than $0.80 \mathrm{~g} / \mathrm{MJ} \mathrm{ME}$, and that different levels of those AAs did not affect feed conversion.

In the above experiments, different Met levels were achieved by supplementing the basal diet with a synthetic source of dietary Met, such as DL-Met or its corresponding hydroxy analog, DL-2 hydroxy-(4-methylthio)butanoic acid (DLHMB). The bioefficiency of DLHMB compared with DL-Met has been the subject of numerous studies and still remains controversial (Martin-Venegas et al., 2006). A meta-analysis of published experiments (Vedenov and Pesti, 2010) has revealed 79\% relative biological efficiency of HMTBA for DL-Met. Some experiments have shown that DLHMTB supplementation improves the oxidative status of broiler chickens (Swennen et al., 2011) and is more efficient in alleviating heatinduced oxidative damage compared with DL-Met supplementation (Willemsen et al., 2011).

\section{Effect of sulfur-containing AAs on the immune system of poultry}

It is known that dietary characteristics can modulate a bird's susceptibility to infectious challenges, and subtle influences due to the level of nutrients or the types of ingredients may at times be of critical importance (Klasing, 1998; Kidd, 2004; Kogut, 2009). It is likely that nutrients influence several or all aspects of the immune system, including many metabolic pathways. The classic functional measurements of the immune response include serum antibody titres or humoral immune responses to primary or secondary (booster) immunization, blood levels of different lymphocyte subsets as well as serum concentrations of cytokines and other immune mediators, the weights of lymphoid organs, and morbidity and recovery from infectious diseases (Li et al., 2007).

According to numerous experiments and review articles (Brosnan and Brosnan, 2006; Li et al., 2007; Baker, 2009; Bunchasak, 2009; Mirzaaghatabar et al., 2011; Hosseini et al., 2012; Wu et al., 2012), many AAs play a dual role, nutritional and immunostimulatory. A new concept of functional AAs has been proposed recently. Functional AAs are defined as those AAs that participate in and regulate key metabolic pathways to improve health, survival, growth, development, lactation, and reproduction of organisms (Wu et al., 2013). According to this concept, the group of functional AAs is inclusive of essential AAs, but also of conditionally essential and nutritionally nonessential AAs (Table 3 ).

According to the classification in Table 3, the F-AA group includes dietary Met + Cys. Sufficient dietary intake of both sulfur-containing AAs is important for 
protein synthesis in cells of the immune system (Grimble, 2006). Cys, however, should not be included in the diet at very high concentrations (Li et al., 2007).

Table 3. Classification of amino acids (AAs) in poultry nutrition (according to Wu et al., 2013)

\begin{tabular}{c|c|c|c|c|c}
\hline \multicolumn{6}{c}{ Amino acid } \\
\hline EAA & F- EAA & CEAA & F-CEAA & NEAA & F-NEAA \\
\hline His & Arg & Gln & Glu & Ala & Asp \\
Ile & Cys & & Tau & Asn & \\
Lys & Gly & & & Ser & \\
Phe & Leu & & & & \\
Thr & Met & & & & \\
Val & Pro & & & \\
& Trp & & & \\
& Tyr & & & \\
& & & & & \\
\hline
\end{tabular}

${ }^{1}$ EAA - nutritionally essential, F-EAA - nutritionally essential - functional, CEAA - conditionally essential, F-CEAA - conditionally essential - functional, NEAA - nutritionally nonessential, F-NEAA - nutritionally nonessential - functional.

Takahashi et al. (1997) demonstrated that both sulfur-containing AAs (Met and Cys) have a beneficial influence on immune and inflammatory responses. As indicated above, the cited authors used two dietary levels of Cys $(0.185$ or $0.37 \%)$ and found that mononuclear cell proliferation in the spleen induced by concanavalin $\mathrm{A}$ in chicks fed the higher-cysteine diet was greater than that in chicks fed the low-cysteine diet. In another experiment (Tsiagbe et al., 1987), dietary supplementation with Met or Cys was beneficial for the immune system under various catabolic conditions. Increasing dietary levels of Met (from 0.4 to $0.6,1.2$ and $1.8 \%$ ) in diets fed to chickens infected with the Newcastle disease virus markedly enhanced T cell proliferation in response to mitogen stimulation, and plasma levels of immunoglobulin $\mathrm{G}$. An increased level of dietary Cys (from 0.185 to $0.37 \%$ ) provided similar effects as Met with regard to the immune responses of chickens. However, high supplemental levels of Met and Cys (1.8 and $0.37 \%$, respectively) were detrimental to the growth and immune responses of chickens. This was probably due to the excess production of highly toxic substances, e.g. homocysteine and sulfuric acid (Wu and Meininger, 2002). For these reasons, a higher Cys content of the diet is considered to be toxic (Li et al., 2007).

According to Swain and Johri (2000), Met plays a key role in the humoral and cellular immune responses of poultry. It is known that AAs are needed for clonal proliferation of lymphocytes, establishment of germinative centres in the bursa of Fabricius to refine immunoglobulin affinity, recruitment of new bone marrow monocytes and heterocytes, and synthesis of effector molecules (immunoglobulins, nitric oxide, lysozyme, complement) and communication molecules (e.g. cytokines and eicosanoids). One of the mechanisms proposed to explain Met interference in the immune system is based on the proliferation of immune cells that are sensitive to intracellular variations in the levels of glutathione and Cys levels, compounds which also participate in Met metabolism (Shini et al., 2005). 
According to Bunchasak (2009), an increased Met content, above the level required for optimal growth, improves the immune response through direct effects (protein synthesis and breakdown) and indirect effects involving Met derivatives. Since leukocytes are important targets for the action of AAs, of particular interest is the response of the adaptive (acquired) immune system consisting of T cells, B cells and humoral factors (Calder, 2006). Particular attention is paid to the thymus, which is the site of $\mathrm{T}$ cell differentiation and development.

Wu et al. (2012) demonstrated that Met deficiency in the diet can impair cellular immune function in broilers by ultrastructural pathological changes in the thymus, decreased $\mathrm{T}$ cell populations, reduction in the serum concentrations of interleukine-2 and $\mathrm{T}$ cell proliferation through an increase in the percentage of apoptotic cells (Table 4).

Table 4. Immune response of broiler chickens to dietary methionine deficiency (according to Wu et al., 2012)

\begin{tabular}{l|l}
\hline \multicolumn{1}{c}{ Evaluation criterion } & \multicolumn{1}{c}{ Effect of Met deficiency $^{1}$} \\
\hline $\begin{array}{l}\text { Relative thymus weight } \\
\begin{array}{l}\text { Morphological and ultrastructural changes } \\
\text { in the thymus }\end{array}\end{array}$ & $\begin{array}{l}\text { Significantly decreased } \\
\text { Decrease in the number of lymphocytes in the medulla of } \\
\text { the thymus lobule, increased apoptosis of lymphocytes and } \\
\text { the mitochondria of lymphocytes in the thymus }\end{array}$ \\
Thymic cell cycle and apoptosis & $\begin{array}{l}\text { DNA replication delay, significantly higher percentage of } \\
\text { apoptotic cells }\end{array}$ \\
Peripheral blood T cell subsets & $\begin{array}{l}\text { Decreased percentages of CD } \\
\text { T cell proliferation }\end{array}$ \\
Serum interleukin-2 (IL-2) & $\begin{array}{l}\text { Decreased mitogenesis of peripheral blood T cells } \\
\text { Lower serum content of IL-2 }\end{array}$ \\
\hline
\end{tabular}

${ }^{1}$ Starter and grower diets with $0.26 \%$ Met versus control diets with 0.50 and $0.40 \%$ Met, respectively.

Another organ of the immune system in poultry is the bursa of Fabricius - the primary lymphoid organ responsible for the establishment and maintenance of the B cell compartment in avian species. Wu et al. (2013) reported that Met-deficient diets reduced the relative weight of the bursa of Fabricius and the number of lymphocytes in the follicles contributed to mitochondrial swelling, and decreased the proliferation index of lymphocytes. The authors concluded that Met deficiency restrained the development of the bursa of Fabricius and affected the humoral immunity of chickens.

As shown in Table 5, different levels of sulfur-containing AAs and different criteria for evaluating the immune responses of birds were used in experiments on chickens. Met concentrations in starter diets ranged from 0.3 to $1.2 \%$, and in grower diets - from 0.3 to $0.9 \%$. The immune response was observed mostly at higher dietary Met levels (over 0.5\%). According to Swain et al. (2000), Rama Rao et al. (2003) and Deng et al. (2007), commercial broiler chickens do not require more than $0.5 \% \mathrm{Met}$ for optimum growth and feed efficiency in the starter period, but higher Met levels are needed to stimulate immune responses. 


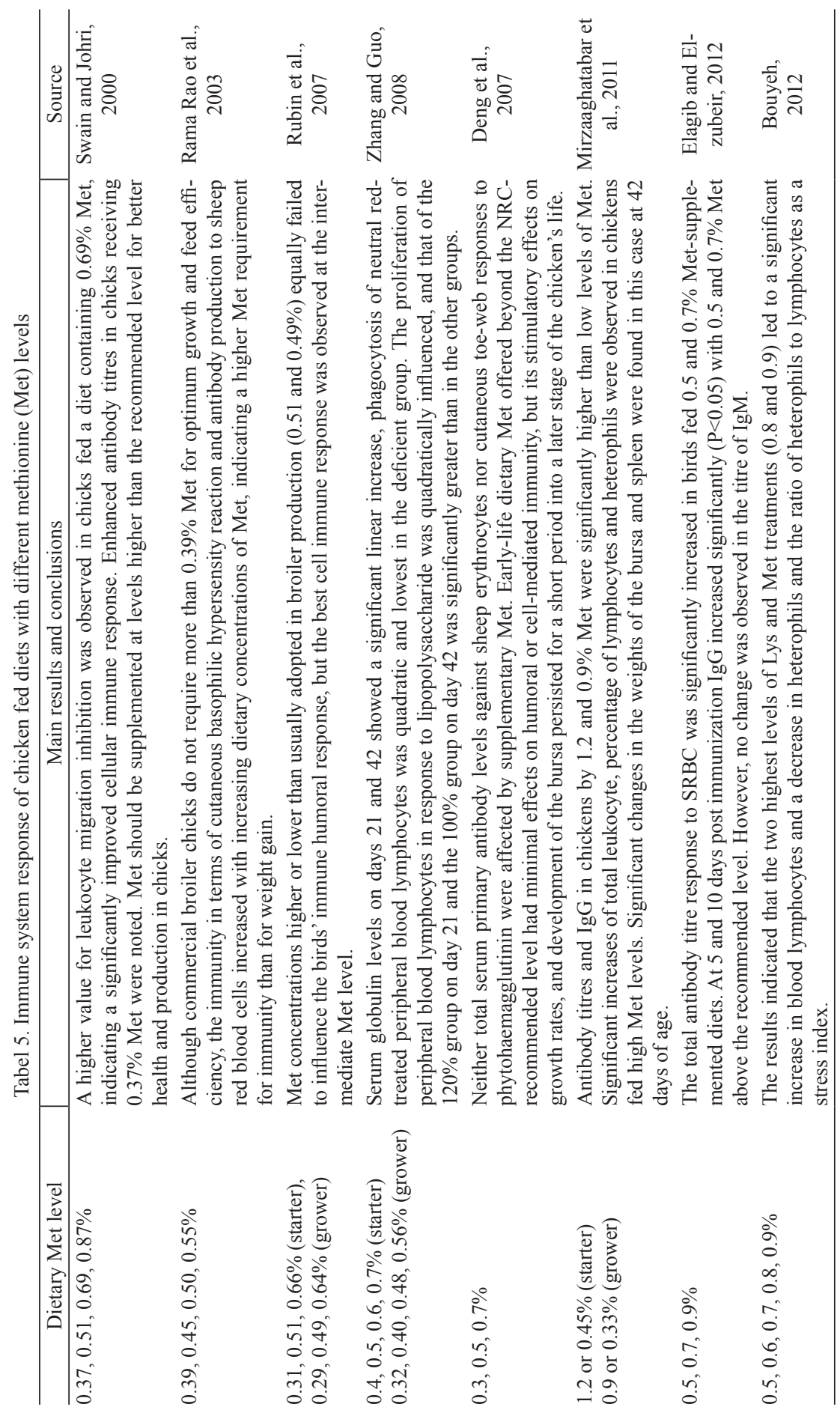


The results of recent experiments on chickens are insufficient to define the optimal dietary levels of Met, which has been shown to exert immunostimulatory activity. According to some authors (Swain et al., 2000; Rama Rao et al., 2003; Deng et al., 2007; Maroufyan et al., 2010), the dietary levels of Met recommended by NRC are not sufficient to meet the requirements of modern commercial poultry. However, the above authors have not specified the optimal Met inclusion rates in poultry diets. This problem is illustrated in Table 6, which shows the results of experiments where Met content varied widely from 0.4 to $0.7 \%$ during the starter period and from 0.32 to $0.56 \%$ during the grower period.

Table 6. Immune responses of broiler chickens fed diets with different Met levels (according to Zhang and Guo, 2008)

\begin{tabular}{l|cccc}
\hline & \multicolumn{4}{|c}{ Dietary methionine levels (starter/grower diet) (\%) } \\
\cline { 2 - 5 } & $0.40 / 0.32$ & $0.50 / 0.40$ & $0.60 / 0.48$ & $0.70 / 0.56$ \\
\hline Relative thymus weight at 42 days (\% BW) & 2.70 & 2.62 & 2.94 & 2.49 \\
Relative spleen weight at 42 days (\% BW) & $0.80 \mathrm{a}$ & $0.85 \mathrm{ab}$ & $0.98 \mathrm{~b}$ & $0.89 \mathrm{ab}$ \\
Serum albumin content (g/L) & 27.34 & 26.03 & 26.82 & 27.22 \\
Serum globulin content (g/L) & $7.91 \mathrm{~b}$ & $8.55 \mathrm{ab}$ & $8.87 \mathrm{ab}$ & $10.88 \mathrm{a}$ \\
Proliferation of lymphocytes & $1.09 \mathrm{a}$ & $1.19 \mathrm{~b}$ & $1.14 \mathrm{ab}$ & $1.09 \mathrm{a}$ \\
Phagocytosis of neutral red-treated peripheral & & & & \\
blood lymphocyte & $0.212 \mathrm{~b}$ & $0.306 \mathrm{a}$ & $0.249 \mathrm{ab}$ & $0.259 \mathrm{ab}$ \\
Lysozyme (mg/L) & $3.47 \mathrm{ab}$ & $4.34 \mathrm{a}$ & $3.03 \mathrm{ab}$ & $3.04 \mathrm{~b}$ \\
Serum antibody titres to BSA & $0.605 \mathrm{~b}$ & $0.615 \mathrm{~b}$ & $0.643 \mathrm{a}$ & $0.600 \mathrm{~b}$ \\
\hline
\end{tabular}

Table 6 data show that an increased Met content of chicken diets did not result in clear, consistent changes in the analysed immunological parameters. The cited authors concluded that 0.4 and $0.32 \%$ dietary Met levels (during the starter and grower periods, respectively), were adequate for optimal growth, and that increased dietary levels of Met (in the form of liquid DL-2-hydroxy-4-methylthio butanoic acid) improved feed utilization and humoral and nonspecific immunocompetence of broiler chickens (Zhang and Guo, 2008).

In a study by Bouyeh (2012), immune system function was improved due to an increase in Met content from 0.50 to 0.65 and $0.70 \%$ in the starter period, and from 0.40 to 0.52 and $56 \%$ in the grower period. In another experiment (Dahiya, 2007), an increase in dietary Met levels from 0.40 to $0.80 \%$ induced positive changes in the caecal microflora of chickens (reducing the counts of Clostridium perfringens and increasing the counts of Streptococcus). The results of the above study indicate that significant health effects are obtained with very high levels of Met, almost twice higher than those recommended to meet the growth needs of chickens.

In one of the few experiments investigating the response of layer hens to different dietary levels of Met (Panda et al., 2007), the effects of three different levels of Met $(0.30,0.36$ and $0.42 \%)$ were compared. It was concluded that Met requirements for immune competence $(0.36 \%)$ are higher than for optimum production $(0.30 \%)$. In a later experiment by Hosseini et al. (2012), six dietary levels of Met $(0.2,0.25,0.3$, $0.35,0.4$ and $0.45 \%$ ) were compared. Different inclusion rates of Met did not affect 
cell-mediated responses, Newcastle and bursal disease titres, and IgM, but the total antibody titre against sheep red blood cells and IgG responses were influenced. The above findings can be summarized as follows: Met requirements for settable eggs were similar to those needed for the optimum immune responses. Since settable eggs are an important factor in broiler breeder industries, the authors recommend higher Met content $(0.49 \%)$ for broiler breeder hens than those needed for optimal egg mass and feed conversion ratio.

One of the few works concerning dietary Met content and turkey resistance to environmental factors was published almost 40 years ago. Murillo and Jensen (1976) demonstrated that the Met requirement for optimum growth, feed efficiency, and prevention of dermatitis was approximately $0.6 \%$, i.e. higher than the contemporary NRC recommendations. Later research has shown that dietary Zink-Met enhances mononuclear-phagocytic function in young turkeys (Kidd et al., 1994; Chien et al., 2006). The findings of research investigating the impact of the dietary levels of Met and/or other AAs on immune system function in turkeys were published in the last decade.

In the above experiments, the immunomodulatory activity of Met was evaluated relative to the NRC recommendations (1994). In most cases, the growth performance and productivity of birds did not improve when Met inclusion levels were increased above the NRC recommendations (1994); differences were noted only with respect to immune responses. Thus, it seems important to determine whether the concentrations of Met and other AAs should be increased in poultry diets without the evaluation of immune system parameters. Special attention should be paid to turkeys, due to considerable differences in the recommended Met levels in their diets (NRC, GfE and B.U.T.) and the absence of studies investigating the immune responses of turkeys to different inclusion rates of AAs, in particular Met.

The discussed method of stimulating the immune system of poultry increases feed costs (Klasing, 2004). It has been postulated that a moderately effective immune response may provide the greatest responsiveness to infections, taking into account the response to a pathogen and the age of birds (Kogut, 2009).

\section{References}

B a k e r D.H. (2009). Advances in protein-amino acid nutrition of poultry. Am. Aci., 37: $29-41$.

B o u y e h M. (2012). Effect of excess lysine and methionine on immune system and performance of broilers. Ann. Biol. Res., 3: 3218-3224.

B rosnan J.T., Brosnan M.E. (2006). The sulfur-containing amino acids: an overview. J. Nutr., 136: $1636-1640$.

Bunchasak C. (2009). Role of dietary methionine in poultry production. J. Poultry Sci., 46: $169-179$.

BUT (2012). Commercial Performance Goals. http://www.aviagen.com/home.aspx?siteId=8

C a ld e r P.C. (2006). Branched-chain amino acid and immunity. J. Nutr., 136: 288S-293S.

Chien X.X., Zafira-S tone S., B a g chi M., B a g chi D. (2006). Bioavailability, antioxidant and immune-enhancing properties of zinc methionine. BioFactors, 27: 231-244.

Conde-Aguilera J.A., Cobo-Ortega C., Tesseraud S., Lessire M., Mercier Y., Milgen J. (2013). Changes in body composition in broilers by a sulfur amino acid deficiency during growth. Poultry Sci., 92: 1266-1275. 
Crhanova M., Hradecka H., Faldynova M., Matulova M., Havlickova H., S i s a k F., Ry chlik I. (2011). Immune response of chicken gut to natural colonization by gut microflora and to Salmonella enteritis serovar enteritidis infection. Infect. Immun., 79: 2755-2763.

Dahiya J.P., Hoehler D., Van Kessel A.G., Drew M.D. (2007). Effect of different dietary methionine sources on intestinal microbial populations in broiler chickens. Poultry Sci., 86: $2358-2366$.

D e n g K., Wo n g C.W., N ola n J.V. (2007). Carry-over effects of early-life supplementary methionine on lymphoid organs and immune responses in egg-laying strain chickens. Anim. Feed Sci. Technol., 134: 66-76.

D un 1 e vy L.P., B urren K.A., Mills K., Chit ty L.S., C op p A.J., Greene N.D. (2006). Integrity of the methylation cycle is essential for mammalian neural tube closure. Birth Defects Res. A. Clin. Mol. Teratol., 76: 544-552.

E 1 a g i b H.A.A., E $1 \mathrm{zu}$ b e ir E.A. (2012). Humoral immune response of broiler chicks fed different levels of methionine and energy under heat stress. Int. J. Poultry Sci., 11: 400-404.

E $\mathrm{m}$ m e r s o n D.A. (1997). Commercial approaches to genetic selection for growth and feed conversion in domestic poultry. Poultry Sci., 76: 1121-1125.

Fang Y.Z., Yang S., Wu G. (2002). Free radicals, antioxidants, and nutrition. Nutrition, 18: $872-879$.

Fang Z., Yao K., Zhang X., Zha o S., S un Z., Tian G., Yu B., Lin Y., Zhu B., Ji a G., $\mathrm{Z}$ h a n g K., Ch en D., Wu D. (2010). Nutrition and health relevant regulation of intestinal sulfur amino acid metabolism. Am. Aci., 39: 633-640.

GfE (1999). Empfehlungen zur Energie-und Nährstoffversorgung der Legehennen und Masthühner (Broiler). DLG Verlag.

GfE (2004). Empfehlungen zur Energie-und Nährstoffversorgung der Mastputen. Proc. Society of Nutrition Physiology, DLG Verlag, 13: 199-233.

G r i m b l e R.F. (2006). The effects of sulfur amino acid intake on immune function in humans. J. Nutr., 136: $1660-1665$.

G r i m b le R.F., Gri m b le G.K. (1998). Immunonutrition: Role of sulfur amino acids, related amino acids, and polyamines. Nutr., 14: 605-610.

H a l s te d C.H., M e dic i V. (2012). Aberrant hepatic methionine methabolism and gene methylation in the pathogenesis and treatment of alcoholic steatohepatitis. Int. J. Hep., 959746: 1-7.

H a sh e m i S.R., D a vo od i H. (2012). Herbal plants as new immuno-stimulator in poultry industry: a review. Asian J. Anim. Vet. Advanc., 7: 104-116.

H a ve n s te in G.B., F er k e t P.R., Q u re sh i M.A. (2003). Growth, livability, and feed conversion of 1957 versus 2001 broilers when fed representative 1957 and 2001 broiler diets. Poultry Sci., 82: $1500-1508$.

Ho ehl e r D., L e m me A., R obers on K., Turner K. (2005). Impact of methionine sources on performance in turkeys. J. Appl. Poult. Res., 14: 296-305.

Hosseini S.A., Zaghari M., Lotfollahian H., Shivazad M., Moraviaj H. (2012). Reevaluation of methionine requirement based on performance and immune responses in broiler breeder hens. J. Poultry Sci., 49: 26-33.

Ito K., Miwa N., Hagiwara K., Yano T., Shimizu-Saito K., Goseki N., Iwai T., Horikaw a S. (1999). Regulation of methionine adenosyltransferase activity by the glutathione level in rat liver during ischemia-reperfusion. Surg. Today, 29: 1053-1058.

J a nk ow sk i J., Z d uńczy k Z., J uśki e wi c z J., K w i e c iński P. (2011 a). The effect of different dietary sodium levels on the growth performance of broiler chickens, gastrointestinal function, excreta moisture and tibia mineralization. J. Anim. Feed Sci., 20: 93-106.

Jankowski J., Lecewicz A., Chwastowska-Siwiecka I., Juśkiewicz J., Zduńc z y k Z. (2011 b). Performance, slaughter value and meat quality of turkeys fed diets with different content of sunflower meal. Arch. Geflügelk., 75 (2): 104-112.

Kidd M.T., Qureshi M.A., Ferket P.R., Thom as L.N. (1994). Dietary zinc-methionine enhances mononuclear-phagocytic function in young turkeys. Biol. Trace Eleme. Res., 42: 217-229.

K i d d M.T. (2004). Nutritional modulation of immune function in broilers. Poultry Sci., 83: 650-657.

K i m W.K., F r o e l i c h Jr C.A., P a t t e r s o n P.H., R i c k e S.C. (2006). The potential to reduce poultry nitrogen emissions with dietary methionine or methionine analogues supplementation. World's Poultry Sci. J., 62: 338-353. 
K la s ing K.C. (1998). Nutritional modulation of resistance to infectious diseases. Poultry Sci., 77: 1119-1125.

K l a s ing K.C. (2004). The costs of immunity. Acta Zool. Sin., 50: 961-969.

K o g u t M.H. (2009). Impact of nutrition on the innate immune response to infection in poultry. J. Appl. Poultry Res., 18: 111-124.

Kore leski J., Św i ątki ew i c z S. (2008). Effect of protein methionine levels in a semi-organic diet for dual-purpose type chickens on slaughter performance and nitrogen balance. J. Anim. Feed Sci., 17: 381-391.

Lara L.J., Rostagno M.H. (2013). Impact of heat stress on poultry production. Animals, 3: $356-369$.

Lem me A., Kozłowski K., Jankowski J., Petri A., Zduńczyk Z. (2005). Responses of 36 to 63 day old BUT Big 6 turkey toms to graded dietary methionine + cysteine levels. J. Anim. Feed Sci., 14: Suppl. 1: 139-142.

L e s h c h in s k y T.V., K l a s ing K.C. (2001). Divergence of the inflammatory response in two types of chickens. Dev. Comp. Immunol., 25: 629-663.

Li P., Y in Y-L., Li D., K i m S.W., W u G. (2007). Amino acids and immune function. Brit. J. Nutr., 98: 237-252.

L u o S., L e vin e R.L. (2009). Methionine in proteins defends against oxidative stress. FASEB J., 23: $464-472$.

Mar ou fy a n E., Ka s i m A., H a s he m i S.R., L o h T.C., B e jo M.H., D a vo od i H. (2010). The effect of methionine and threonine supplementations on immune response of broiler chickens challenged with infectious bursal disease. Am. J. Appl. Sci., 7: 44-50.

Martin-Ven e gas R., G era ert P.A., F e rre r R. (2006). Conversion of the methionine hydroxy analogue dl-2-hydroxy-(4-methylthio) butanoic acid to sulfur-containing amino acids in the chicken small intestine. Poultry Sci., 85: 1932-1938.

Mashaly M.M., He etkamp M.J., Parmentier H.K., S chrama J.W. (2000). Influence of genetic selection for antibody production against sheep red blood cells on energy and metabolism in laying hens. Poultry Sci., 79: 519-524.

Matsushita K., Takahashi K., Akiba Y. (2007). Effects of adequate or marginal excess of dietary methionine hydroxyl analogue free acid on growth performance, edible meat yields and inflammatory response in female broiler chickens. J. Poultry Sci., 44: 265-272.

Meirelles H.T., Albuquerque R., Borgatti L.M.O., Souza L.W.O., Meister N.C., L i m a F.R. (2003). Performance of broilers fed with different levels of methionine hydroxyl analogue and DL-methionine. Braz. J. Poultry Sci., 5: 69-74.

Mikulski D., Jankowski J., Zduńczyk Z., Wróblewska M., Sartowska K., Maj ew s k a T. (2009). The effect of selenium source on performance, carcass traits, oxidative status of the organism, and meat quality of turkeys. J. Anim. Feed Sci., 18: 518-530.

Mikulski D., Jankowski J., Zduńczyk Z., Juśki ewicz J., Słominski B.A. (2012). The effect of different dietary levels of rapeseed meal on growth performance, carcass traits, and meat quality in turkeys. Poultry Sci., 91: 215-223.

Mikulski D., Jankowski J., Juśki ew icz J., Mikulska M., Z duńczyk Z. (2014). The effect of different dietary levels of lupin seeds (L. angustifolius and L. luteus) on growth performance, GIT development, and meat quality in growing-finishing turkeys. Anim. Feed Sci. Technol. (in press).

Mirza ghat abar F., Saki A.A., Z a mani P., A liarabi H., Hem at i Matin H.R. (2011). Effect of different levels of diet methionine and metabolisable energy on broiler performance and immune system. Food Agr. Immunol., pp. 1-11.

M o ore D.T., B a ker K., F ir m a n J.D. (2004). Digestible sulfur amino acid requirement for male turkeys from six to twelve weeks of age. J. Appl. Poultry Res., 13: 155-162.

M uri 11 o M.G., J e n s e n L.S. (1976). Methionine requirement of developing turkeys 8-12 weeks of age. Poultry Sci., 55: 1414-1418.

NRC (National Research Council) (1994). Nutrient requirements of poultry. 9th revised edn. National Academic Press, Washington, DC.

P a n d a A.K., R a m a R a o S.V., R a ju M.V.L.N., B h a nj a S.K. (2007). Relative performance and immune response in white leghorn layers fed liquid DL-methionine hydroxy analogue and DLmethionine. Asian-Aust. J. Anim. Sci., 6: 948-953. 
Rad oj a S., Frey A.B., Vu k m a n o v i c S. (2006). T-cell receptor signaling events triggering granule exocytosis. Crit. Rev. Immunol., 26: 265-290.

R a m a R a o S.V., Praharaj N.K., R eddy M.R., P and a A.K. (2003). Interaction between genotype and dietary concentrations of methionine for immune function in commercial broilers. Br. Poultry Sci., 44: 104-112.

R o s s (2007). Broiler Nutrition Specification. http://www.en.aviagen.com/assets/Tech_Center/Ross_ Broiler/Ross_308_Broiler

Rubin L.L., Can a 1 C.W., Ribeiro A.L.M., K e s s le r A., S ilva I., Trevizan L., Viola T., Raber M., Goncalves T.A., Kras R. (2007). Effects of methionine and arginine dietary levels on the immunity of broiler chickens submitted to immunological stimuli. Br. J. Poultry Sci., 9: 241-247.

R u th M.R., F i e ld C.J. (2013). The immune modifying effects of amino acids on gut-associated lymphoid tissue. J. Anim. Sci. Biotechnol., 42, p. 27.

S h i n i S., Li X., B r y d e n W.L. (2005). Methionine requirement and cell-mediated immune in chicks. Asia Pac. J. Clin. Nutr., 14 (Suppl) S123.

S proul T.W., Cheng P.C., D y k s tra M.L., P i e r c e S.K. (2000). A role for MHC class II antigen processing in B cell development. Int. Rev. Immunol., 19: 139-155.

S w a in B.K., J o hri T.S. (2000). Effect of supplemental methionine, choline and their combinations on the performance and immune response of broilers. Br. Poultry Sci., 41: 83-88.

Swennen Q., Geraert P-A., Mercier Y., Everaert N., S tinckens A., Willemsen H., Li Y., D e cuypere E., B u y s e J. (2011). Effects of dietary protein content and 2-hydroxy-4-methylthiobutanoic acid or DL-methionine supplementation on performance and oxidative status of broiler chickens. Brit. J. Nutr. 106: 1845-1854.

Ta k a ha s hi K., O h t a N., A k i b a Y. (1997). Influences of dietary methionine and cysteine on metabolic responses to immunological stress by Escherichia coli lipopolysaccharide injection, and mitogenic response in broiler chickens. Brit. J. Nutr., 78: 815-821.

Troen A.M., Lutgen s E., S m ith D.E., Ros en berg I.H., S e 1 h u b J. (2003). The atherogenic effect of excess methionine intake. Proc. Natl. Acad. Sci. USA, 100: 15089-15094.

T s i a g b e V.K., C o o k M.E., H a r p e r A.E., S un d e M.L. (1987). Efficacy of cysteine in replacing methionine in the immune responses of broiler chicks. Poultry Sci., 66: 1138-1146.

Vedenov D., Pesti G.M. (2010). An economic analysis of a methionine source comparison response model. Poultry Sci., 89: 2514-2520.

Wa 1 d r o u p P.W., A d a m s P.W., Wa ld r o u p A.L. (1997). Evaluation of National Research Council amino acid recommendations for Large White turkeys. Poultry Sci., 76: 711-720.

Wa 11 w o r k J.C., D u e r r e J.A. (1985). Effect of zinc deficiency on methionine metabolism, methylation reactions and protein synthesis in isolated perfused rat liver. J. Nutr., 115: 252-262.

Waterland R.A. (2006). Assessing the effects of high methionine intake on DNA methylation. J. Nutr., 136: 1706-1710.

We b b R.E., L e s li e Jr D.M., L o chmille r R.L., M a s ters R.E. (2003). Immune function and hematology of male cotton rats (Sigmodon hispidus) in response to food supplementation and methionine. Comp. Bioch. Ph. P. A., 136: 577-589.

We r s h il B.K., F u r u t a G.T. (2008). Gastrointestinal mucosal immunity. J. Allergy Clin. Immunol., 121: $380-383$.

Willemsen H., Swennen Q., Everaert N., Geraert P.A., Mercier Y., S tinckens A., Decuypere E., Buyse J. (2011). Effects of dietary supplementation of methionine and its hydroxyl analog DL-2-hydroxy-4-methylthiobutanoic acid on growth performance, plasma hormonal levels, and the redox status of broiler chicken exposed to high temperatures. Poultry Sci., 90: 2311-2320.

W u G., M e in inge r C.J. (2002). Regulation of nitric oxide synthesis by dietary factors. Annu Rev. Nutr., 22: 61-86.

W u G. (2010). Functional amino acids in growth, reproduction, and health. Adv. Nutr., 1: 31-37.

Wu B., Cui H., Peng X., Fang J., Cui W., Li u X. (2012). Effect of methionine deficiency on the thymus and the subsets and proliferation on peripheral blood T cell, and serum IL 2 in broilers. J. Int. Agri., 11: 1009-1019.

W u G. (2013). Functional amino acids in nutrition and health. Amino Acids, 45: 407-411. 
Wu B., Cui H., Peng X., Fang J., Cui W., Li u X. (2013). Pathology of bursa of Fabricius in methionine-deficient broiler chickens. Nutrients, 5: 877-886.

Yasuhiko K., Sakamoto S., Kas ahara T., Kusumoto K., Hida K., Suda K., Ozawa K., Mi ura Y., Tak a F. (1982). Methionine dependency of cell growth in normal and malignant hematopoietic cells. Cancer Res., 42: 3090-3092.

Z h a n g L.B., G u o Y.M. (2008). Effects on liquid DL-2-hydroxy-4-methylthio butanoic acid on growth performance and immune responses in broiler chickens. Poultry Sci., 87: 1370-1376.

Accepted for printing 25 XI 2013 
